\title{
Evaluation of Taping in the Lymphatic System through Lymphoscintigraphy of Upper and Lower Limbs: A Case Study
}

\author{
Maria da Glória Karan Marquetti1,2, Anny Chi1 ${ }^{1}$, Cristiano Ferrari Siqueira ${ }^{3}$, Ian Fidelis Santos ${ }^{4}$ \\ ${ }^{1}$ IUNIR, AR, Ponta Grossa, Brasil \\ ${ }^{2}$ The Physical Therapy Course, CESUFOZ, Foz do Iguaçu, Brasil \\ ${ }^{3}$ Medicine UNILA, Foz do Iguaçu, Brasil \\ ${ }^{4}$ Faculty of Medicine Americas, Sao Paulo, Brazil \\ Email: gloriamarquetti@gmail.com
}

How to cite this paper: Marquetti, M.G.K., Chi, A., Siqueira, C.F. and Santos, I.F. (2019) Evaluation of Taping in the Lymphatic System through Lymphoscintigraphy of Upper and Lower Limbs: A Case Study. Health, 11, 527-534.

https://doi.org/10.4236/health.2019.115045

Received: April 15, 2019

Accepted: May 24, 2019

Published: May 27, 2019

Copyright ( 2019 by author(s) and Scientific Research Publishing Inc. This work is licensed under the Creative Commons Attribution International License (CC BY 4.0).

http://creativecommons.org/licenses/by/4.0/

\section{c) (i) Open Access}

\begin{abstract}
Introduction: Lymphatic taping has been used extensively in several areas of physical therapy, and has been prominent in the treatment of edema. Its results are considered empirical and no study reports its effect observed by a lymphocyte count study. Purpose: To verify the performance of lymphatic taping in the lymphatic system using lymphoscintigraphy examination. Methods: A 44-year-old male patient with no clinical signs of lymphatic alteration underwent lymphoscintigraphy examination prior to and after application of lymphatic taping in the upper and lower limbs on different days of placement to verify if the use of lymphatic taping may influence the lymph flow. Results: The result was an improvement in the lymphatic flow with application of lymphatic taping only in the lower limbs, where the taping acted only for 24 hours. There was a greater amount of radiopharmaceutical extracted in the feet of the patient, comparing pre- and post-application of taping. At the foot of the left lower limb, the absorption ratio doubled. There was also improvement in the right limb, but on a smaller scale. Conclusion: Through the evaluation of the lymphatic system by lymphoscintigraphy it can be observed that the values analyzed are relatively higher when the patient has lymphatic taping applied with both $10 \%$ and $20 \%$ of tension in the lower limbs.
\end{abstract}

\section{Keywords}

Taping, Lymphatic System, Lymphoscintigraphy

\section{Introduction}

The lymphatic system is a system that works in conjunction with the circulatory 
system and constitutes a unidirectional transport, its main function being the excessive transport of interstitial fluid from the interstitial space to the circulation via the thoracic duct [1] [2]. Any change in the normal functioning of this system can lead to an accumulation of interstitial fluid generating edema [3].

Numerous treatments are used to reduce congestion of the lymphatic system, from manual resources such as manual lymphatic drainage, among other resources and equipment that we call the pre-therapy therapy, RAGodoy ${ }^{\otimes}$ as well as taping [4]. Among these resources, taping has been prominent in several areas of physical therapy, plastic surgery, aesthetics, neurology, pediatrics and orthopedics, speech therapy among others [4]-[10].

As an agent in the stimulation of the lymphatic system with consequent reduction of edema, taping is a form of neuromuscular bandage, with several indications, presenting expressive clinical results for the treatment and prevention of edema as already described in the literature [11] [12] [13].

It should be applied according to the anatomy of the lymphatic flow, with the cut in 4 or 5 strips in the form of an octopus or fan, which is applied with minimum tension, and has shown satisfactory results since its application in transoperative as observed and described in scientific articles [14].

Its physiological effects on the lymphatic system are still reported empirically, but some authors mention that after its application there is an increase in the velocity of lymphatic and venous microcirculation, reducing lymphatic congestion in the intercellular spaces [15] [16] [17] [18] [19]. Due to the fact of increasing the space between the skin and muscle tissue, promoting the opening of the initial lymphatic vessels and the sliding of the skin over the fascia, the mechanism contributes to the improvement of the lymphatic and venous circulation [20] [21] [22].

Some forms of scientific evidence for the evaluation of the physiological effects of taping have already been performed, such as ultrasound, perimetry, etc., but nothing is considered as a gold standard for lymphatic system analysis such as lymphoscintigraphy, which is a representative exam for objective evaluation, quantitative and diagnostic of the lymphatic system at the extremities. The planning of clinical or surgical treatment and the evaluation of therapeutic efficacy can be aided by lymphoscintigraphic information [23] [24].

Lymphoscintigraphy Scanning marks the route of lymphatic vessels and can be used to assess the effectiveness of taping to the lymphatic system, and it is possible to mark the lymphatic system via radiopharmaceuticals 4 . The mapping of the body distribution of the radiopharmaceutical is done by a scintillation chamber, which captures the gamma rays emitted by radionuclides [24].

Thus lymphoscintigraphy becomes the gold standard examination for the analysis of post-application results of taping in the lymphatic system.

In order to verify the effectiveness of lymphatic taping in lymph conduction, a two-stage lymphoscintigraphy exam was performed in this case study. First, no taping was used, and another stage with lymphatic taping was used to compare 
and verify lymph node velocity and transport of the drug through the lymphatic system.

\section{Case Presentation}

A 44-year-old male patient, with no clinical signs of lymphatic alteration, was submitted to lymphoincinography examination before and after taping in the upper and lower limbs for later analysis of taping efficiency. In a first step the patient underwent lymphoscintigraphy without taping and after one week the examination, but with taping, in the upper and lower limbs was performed to evaluate the time and speed of the conduction of the drug radio from the injected site to the near the lymph node site.

\section{Methodology}

The taping was applied to the upper limbs 4 days in advance of the lymphoscintigraphy examination, positioned with the fan cut or octopus (5 tails). Three portions of taping were placed on the right and left upper limbs, all with the base close to the axillary lymph node region and three portions of taping in the right and left forearm, with the bases in the ulnar lymph node region. All placements followed the physiological sense of the lymphatic system. In the right upper limb was placed the taping with the paper-off technique (10\% of tension) and in the upper left limb was placed with taping removal and immediate bonding (20\% tension) (Figure 1 and Figure 2).

The taping was applied to lower limbs 24 hours before the lymphoscintigraphy examination, positioned with the fan cut or octopus ( 5 tails). Three portions of taping were placed on the right and left thigh, all with the base close to the region of inguinal lymph nodes and three portions of taping in the right and left leg, with bases in the region of popliteal lymph nodes. All placements followed the physiological sense of the lymphatic system. Taping was applied with the paper-off technique (10\% tension) in both lower limbs (Figure 3 and Figure 4).

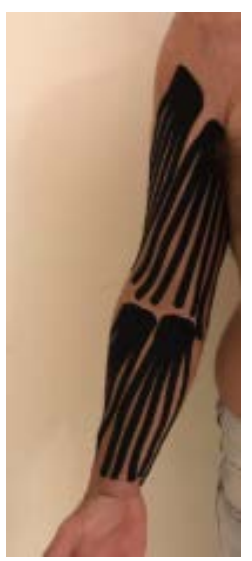

Figure 1. Taping cut fan or octopus ( $10 \%$ tension) in limb upper right. 


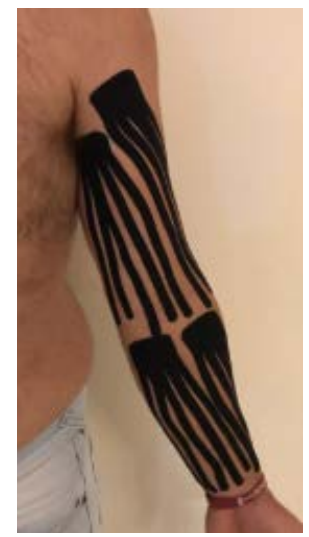

Figure 2. Taping cut fan or octopus (20\% tension) in limb upper left.

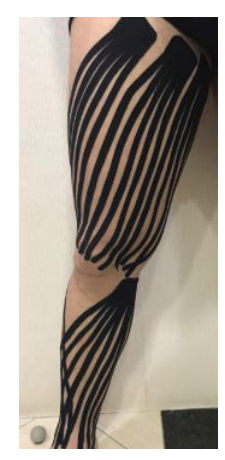

Figure 3. Taping cut fan or octopus (10\% tension) in limb lower right.

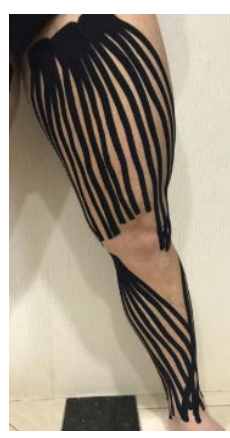

Figure 4. Taping cut fan or octopus (10\% tension) in limb lower left.

The technique for obtaining lymphoscintigraphy was performed in both upper and lower limbs for comparison purposes. The patient remained supine. 74 Megabequeréis (MBq) of $99 \mathrm{mTc}$-dextran, $1.0 \mathrm{~mL}$ per member, were injected into the subcutaneous region of the 2 nd and 4 th interdigital spaces at the same time. The initial scintigraphic images consist of a dynamic acquisition for 15 minutes of the inguinal region. Two previous and posterior scans of the limbs were obtained after 30 minutes and 3 hours after the injection of the radiopharmaceutical (Figure 5). 


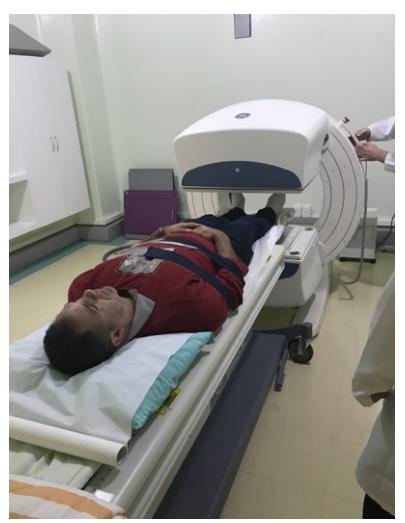

Figure 5. Patient performing Lymphoscintigraphy examination.

Additional images (early and late) of the pelvis and feet and axillary region and hands can be acquired for quantitative evaluation.

Quantitative studies of radiopharmaceutical site injection $(R C)$ and inguinal node $(N U)$ capture were obtained for the following equations:

$$
\begin{gathered}
R C=\frac{[I I S \times 0.71]-L S I}{I I S \times 0.71} \\
N U=\frac{\text { Late inguinal node uptake }}{I I S \times 0.71}
\end{gathered}
$$

$R C$ : clearance in injection site;

$I I S$ : initial uptake in the injection site;

LSI: late uptake in the injection site;

Technetium's correction factor: 0.71 ;

$N U$ : inguinal node uptake.

\section{Results}

The information provided by the initial dynamic images determines the time of lymphatic transit from the injection site to the inguinal ganglionic chain. According to our experience, an interval of less than 10 minutes can be considered physiological.

The analysis of limb scans after 30 minutes shows an accumulation of the radiopharmaceutical at the sites of injection, the symmetrical and preferential rise of the same by the lymphatic collectors that accompany the great saphenous vein (anteromedial face of the limbs). The visualized collectors should be studied according to the number and caliber of the vessels. The accumulation of the radiopharmaceutical in the ilium-inguinal ganglionic chains reflects the potency of the lymphatic pathways and the functionality of the local lymph nodes. The ganglion chains must have a similar number of lymph nodes and a symmetrical radiopharmaceutical capturing intensity.

In the scan images after 3 hours, a lower concentration of the radiopharmaceutical was observed at the sites of injection, with greater accumulation in the 
ilium-inguinal and para-aortic chains compared to the initial images. The liver should be visualized in the late images, demonstrating the communication of the thoracic duct with the venous system.

Lymphatic collectors related to the saphenous vein and popliteal lymph nodes are infrequent when identified in the posterolateral region of the leg and in the popliteal fossa, respectively, which may indicate a preferential flow variation or a compromise of lymphatic transit.

Through the evaluation of the lymphatic system by lymphoscintigraphy, it can be observed that the values analyzed are relatively higher when the patient has taping applied. By the absorption index, the left limb extracts less radiopharmaceutical than the right one. There was a greater amount of radiopharmaceutical extracted in the feet of the patient, comparing pre- and post-application of taping.

It is interesting to note that at the foot of the lower left limb, the absorption ratio has doubled. There was also improvement in the right limb but on a smaller scale as shown in Table 1.

In relation to inguinal ganglion uptake, the concentration was lower in the lower left limb in relation to the right in the two evaluations. There was no quantitative change before and after taping as shown in Table 2.

Hypothesis to explain the failure of this indicator would be that the lymph nodes accumulate limited amount of radio drug and these molecules may have taken collateral pathways, not being possible to gauge. Another possibility would be that the absorption of the radioactive drug was so effective that it passed through the inguinal lymph nodes faster with the use of taping.

\section{Conclusion}

Through the evaluation of the lymphatic system by lymphoscintigraphy, it can be observed that the values analyzed are relatively higher when the patient has lymphatic taping applied with both $10 \%$ and $20 \%$ lower limb tension. Other studies with a greater number of participants are necessary for this confirmation, as well as to evaluate the effects of taping according to the days of application, because as verified in this study, the application in four-day upper limbs showed no difference.

Table 1. Bleaching (absorption) at injection sites.

\begin{tabular}{ccc}
\hline & Without Taping & With Taping \\
\hline Right Foot & $\mathrm{RC}=8 \%$ & $\mathrm{RC}=13.5 \%$ \\
left foot & $\mathrm{RC}=3.5 \%$ & $\mathrm{RC}=8 \%$ \\
\hline
\end{tabular}

Table 2. Inguinal ganglion capture.

\begin{tabular}{ccc}
\hline & Without Taping & With Taping \\
\hline Right Pelvis & $\mathrm{NU}=3.2 \%$ & $\mathrm{NU}=2.5 \%$ \\
Left Pelvis & $\mathrm{NU}=1.5 \%$ & $\mathrm{NU}=1.0 \%$
\end{tabular}




\section{Conflicts of Interest}

The authors declare no conflicts of interest regarding the publication of this paper.

\section{References}

[1] Margaris, K.N. and Black, R.A. (2012) Modelling the Lymphatic System: Challenges and Opportunities. Journal of the Royal Society Interface, 9, 601-612. https://doi.org/10.1098/rsif.2011.0751

[2] Hsu, M.C. and Itkin, M. (2016) Lymphatic Anatomy. Techniques in Vascular and Interventional Radiology, 19, 247-254. https://doi.org/10.1053/j.tvir.2016.10.003

[3] Alitalo, K. (2011) The Lymphatic Vasculature in Disease. Nature Medicine, 17, 1371-1380. https://doi.org/10.1038/nm.2545

[4] Godoy, J.M., Iozzi, A.J., Azevedo, W.F. and Godoy, M.F.G. (2012) New Method to Assess Manual Lymph Drainage Using Lymphoscintigraphy. Nuclear Medicine Review, 15, 140-142.

[5] Pop, T.B., Borowska, B.K., Tymczak, M., Halas, I. and Banas, J. (2014) The Influence of Kinesiology Taping on the Reduction of lymphoedema among Women after Mastectomy-Preliminary Study. Contemporary Oncology, 18, 124-129.

https://doi.org/10.5114/wo.2014.40644

[6] Parreira, P.C.S., Costa, L.C.M., Takahashi, R., Hespanhol, L.C., Luz, M.A., Silva, T.M. and Costa, L.O.P. (2014) Kinesio Taping to Generate Skin Convolutions Is Not Better than Sham Taping for People with Chronic Non-Specific Low Back Pain: A Randomised Trial. Journal of Physiotherapy, 60, 90-96.

https://doi.org/10.1016/j.jphys.2014.05.003

[7] Mostafavifar, M., Wertz, J. and Borchers, J. (2012) A Systematic Review of the Effectiveness of Kinesio Taping for Musculoskeletal Injury. The Physician and Sportsmedicine, 40, 33-40. https://doi.org/10.3810/psm.2012.11.1986

[8] Kase, K., Wallis, J. and Kase, T. (2003) Clinical Therapeutic Applications of the Kinesio Taping Method. Ken Ikai Co. Ltd., Tokyo, Japan.

[9] Gursen, C., Inanoglu, D., Kaya. S. and Akbayrak, T. (2015) Effects of Exercise and Kinesio Taping on Abdominal Recovery in Women with Cesarean Section: A Pilot Randomized Controlled Trial. Archives of Gynecology and Obstetrics, 293, 557-565. https://doi.org/10.1007/s00404-015-3862-3

[10] Nelson, N.L. (2016) Kinesio Taping for Chronic Low Back Pain: A Systematic Review. Journal of Bodywork \& Movement Therapies, 20, 672-681.

https://doi.org/10.1016/j.jbmt.2016.04.018

[11] Kaplan, S., Alpayci, M., Karaman, E., Çetin, O., Özkan, Y., İlter, S., Şah, V. and Şahin, H.G. (2016) Short-Term Effects of Kinesio Taping in Women with Pregnancy-Related Low Back Pain: A Randomized Controlled Clinical Trial. Medical Science Monitor, 22, 1297-1301. https://doi.org/10.12659/MSM.898353

[12] Pivetta, H.M.F., Petter, G.N., Penna, G.B., Martins, T.N.O., Santos, L.F. and Pautz, A.C.G. (2017) Efeitos do Kinesio Taping sobre o edema linfá tico (Effects of Kinesiology Taping on the Lymphatic Edema). Fisioterapia Brasil, 18, 382-390. https://doi.org/10.33233/fb.v18i3.1067

[13] Ferrándiz, A., et al. (2014) A Randomized Controlled Trial of a Mixed Kinesio Taping-Compression Technique on Venous Symptoms, Pain, Peripheral Venous Flow, Clinical Severity and Overall Health Status in Postmenopausal Women with 
Chronic Venous Insufficiency. Clinical Rehabilitation, 28, 69-81. https://doi.org/10.1177/0269215512469120

[14] Chi, A., Lange, A., Guimarães, M.V.T.N. and Santos, C.B. (2018) Prevenção e tratamento de equimose, edema e fibrose no pré, trans e pós-operatório de cirurgias plásticas. Revista Brasileira de Cirurgia Plástica (RBCP), 33, 343-354. https://doi.org/10.5935/2177-1235.2018RBCP0147

[15] Martins, J.C., Aguiar, S.S., Fabro, E.A., Costa, R.M., Lemos, T.V., Sá, V.G., Abreu, R.M., Andrade, M.F., Thuler, L.C. and Bergmann, A. (2016) Safety and Tolerability of Kinesio Taping in Patients with Arm Lymphedema: Medical Device Clinical Study. Support Care Cancer, 24, 3277-3278. https://doi.org/10.1007/s00520-016-3169-3

[16] Tsai, H.J., Hung, H.C., Yang, J.L., Huang, C.S. and Tsauo, J.Y. (2009) Poderia fita Kinesio substituir o curativo em terapia linfática decongestiva para o linfedema relacionados com a mama-câncer? Um estudopiloto. Supportive Care Cancer, 17, 1353-1360. https://doi.org/10.1007/s00520-009-0592-8

[17] Smykla, A., Walewicz, K., Halski, T., Kucharzewski, M., Kucio, C., Mikusek, W., Klakla, K. and Taradaj, J. (2013) Effect of Kinesiology Taping on Breast Cancer-Related Lymphedema: A Randomized Single-Blind Controlled Pilot Study. BioMed Research International, 2013, Article ID: 767106. https://doi.org/10.1155/2013/767106

[18] Pekyavaş, N.Ö., Tunay, V.B. Akbayrak, T., Kaya, S. and Karataş, M. (2014) Complex Decongestive Therapy and Taping for Patients with Postmastectomy Lymphedema: A Randomized Controlled Study. European Journal of Oncology Nursing, 18, 585-590. https://doi.org/10.1016/j.ejon.2014.06.010

[19] Tozzi, U., Santagata, M., Sellitto, A. and Tartaro, G.P. (2016) Influence of Kinesiologic Tape on Post-Operative Swelling After Orthognathic Surgery. Journal of Maxillofacial and Oral Surgery, 15, 52-58. https://doi.org/10.1007/s12663-015-0787-0

[20] Bosman, J. and Piller, N. (2010) Lymph Taping and Seroma Formation Post Breast Cancer. Journal of Lymphoedema, 5, 12-21.

[21] Neves, A.C., et al. (2010) Bandas neuromusculares: um complemento na abordagem da fisioterapia mastectomia. Notícias de BandasNeuromusculares.

[22] Ristow, O., Pautke, C., Kehl, V., Koerdt, S., Hahnefeld, L. and Hohlweg, M.B. (2014) Kinesiologic Taping Reduces Morbidity after Oral and Maxillofacial Surgery: A Pooled Analysis. Physiotherapy Theory and Practice, 30, 390-398. https://doi.org/10.3109/09593985.2014.891068

[23] Yoo, J., Choi, J.Y., Hwang, J.H., Kim, Y.W., Choe, Y.S., Lee, K.H. and Kim, B.T. (2014) Prognostic Value of Lymphoscintigraphy in Patients with Gynecological Cancer-Related Lymphedema. Journal of Surgical Oncology, 109, 760-763. https://doi.org/10.1002/jso.23588

[24] Young, H.K., Hwang, J.H., Bae, J.H. and Choi, J.Y. (2019) Predictive Value of Lymphoscintigraphy in Patients with Breast Cancer-Related Lymphedema Undergoing Complex Decongestive Therapy. Breast Cancer Research and Treatment, 173, 735-741. 